DOI 10.37882/2223-2982.2021.03-2.32

\title{
ПЕРЕДАЧА МОДАЛЬНОСТИ ДОЛЖЕНСТВОВАНИЯ ПРИ ПОМОЩИ ГРАММАТИЧЕСКИХ КОНСТРУКЦИЙ В ИСПАНСКОМ ЯЗЫКЕ
}

\section{CONVEYING THE MODALITY OF OBLIGATION BY MEANS \\ OF GRAMMATICAL STRUCTURES IN THE SPANISH LANGUAGE}

Yu. Palii

Summary: The present study is devoted to the issue of the usage of grammatical constructions in conveying the modality of obligation in Spanish. The purpose of this work is to identify the peculiarities of the use of grammatical constructions haber de + infinitivo, hay que + infinitivo, tener que + infinitivo, deber de + infinitivo when conveying the modality of obligation in the novel "Niebla" by the Spanish writer Miguel de Unamuno. The results of the study show that grammatical constructions reflect not only the modality and aspectuality of the action, but also convey different semantic shades of meaning. In the constructions that express the obligation, the subjective-evaluative component is most clearly manifested.

Keywords: subjective modality, obligation, grammatical constructions, infinitive.

\author{
Палий Юлия Владимировна \\ К.п.н., доцент, ФГАОУВО «Севастопольский \\ государственный университет» \\ julmay19@gmail.com
}

Аннотация: Представленное исследование посвящено вопросу использования грамматических конструкций при передаче модальности в испанском языке. Целью данной работы является выявление особенностей употребления грамматических конструкций haber de + infinitivo, hay que + infinitivo, tener que + infinitivo, deber de + infinitivo при передаче модальности долженствования в романе испанского писателя Мигеля де Унамуно «Niebla».

Результаты проведенного исследования показывают, что грамматические конструкции отражают не только модальность и аспектуальность действия, но и передают различные смысловые оттенки. В конструкциях, выражающих долженствование, наиболее ярко проявляется субъективно-оценочный компонент.

Ключевые слова: субъективная модальность, долженствование, грамматические конструкции, инфинитив.

компонент, проявляющийся через отношение говорящего/автора [4].

В испанском языке существует ряд грамматических средств, передающих значение вынужденности, объединенных общей модальностью долженствования, необходимости, и т.п. Мы можем отнести конструкции haber de + infinitivo, hay que + infinitivo, tener que + infinitivo $и$ deber de + infinitivo к грамматизованным конструкциям, выражающим долженствование [1, с. 233].

Например, конструкция haber de + infinitivo выражает долженствование, а также значение необходимости, «следует», «нужно». Конструкция tener que + infinitivo может выражать также необходимость, невозможность избежать действия. Конструкция hay que + infinitivo является безличной. По смыслу она близка к двум предыдущим конструкциям, основным значением которых является долженствование [2, с. 248].

Deber de + infinitivo выражает высокую степень вероятности осуществления действия со значением «должно быть». Следует отметить, что в современном испанском языке наблюдается известная тенденция к функциональному смешению конструкции deber с инфинитивом и 
deber de-инфинитивом [2, с. 251].

Вышеуказанные структуры могут иметь множественные пересечения с другими полями значений, иными словами, могут одновременно принадлежать к нескольким полям. Названные конструкции являются средством передачи субъективной модальности. По мнению автора М.А. Шевцовой «субъективная модальностъ выражает оценку со стороны говорящего о степени познанности объективных связей. В отличие от объективной модальности, отражающей характер связей в самой действительности и потому являющейся составной частью конкретного содержания предложения, субъективная модальность не выступает результатом отражения объективной действительности. Она выражает лишь оценку адекватности этого отражения» [6].

Среди разновидностей модальностей, выражающих субъективную оценку, автор выделяет:

- Эпистемическая модальность знаний (вывод на основе имеющихся знаний и фактов)

- Эпистемическая модальность мнений (вывод на основе имеющихся знаний/фактов, представленный как наиболее вероятный/достоверный)

- Деонтическую модальность (в случае употребления глагола deber) [6].

Таким образом, можно сделать вывод, что в испанском языке ряд модальных конструкций выражает субъективную оценку с точки зрения долженствования, вынужденности или необходимости.

Рассмотрим примеры употребления грамматических конструкций, выражающих долженствование, в романе Мигеля де Унамуно «Niebla».

«Es una desgracia esto de tener que servirse uno de las cosas - pensó Augusto - ; tener que usarlas, el uso estropea y hasta destruye toda belleza. La función más noble de los objetos es la de ser contemplados. ¡Qué bella es una naranja antes de comida!» [5, c. 29].

В первом предложении конструкция tener que + infinitivo передает значение вынужденности, обязательства, идущих извне. Особенно ярко передает состояние смирения с внешними условиями первое предложение, где конструкция tener que + infinitivo употреблена дважды, что подчеркивает, степень осознания главным героем невозможности противостоять обстоятельствам.

"iLa hormiga. ¡bah!, uno de los animales más hipócritas! Apenas hace sino pasearse y hacernos creer que trabaja. Es como ese gandul que va ahí, a paso de carga, codeando a todos aquellos con quienes se cruza, y no me cabe duda de que no tiene nada que hacer. iQué ha de tener que hacer, hombre, qué ha de tener que hacer!» [5, c. 30].
Похожее значение еще одной конструкции haber de + infinitivo можно встретить в монологе Аугусто. В данном случае при помощи грамматического средства передана невозможность сопротивляться течении жизни. Несмотря на то, что данная реплика идет от первого лица и является субъективной, в контексте предложения она может быть несколько обобщенной, передавая безличное значение типа «ничего не поделать», «что поделаешь».

"Ya tiene mi vida una finalidad; ya tengo una conquista que llevar a cabo. ¡Oh, Eugenia, mi Eugenia, has de ser mía!» $[5$, c 42$]$.

В данном предложении конструкция haber de + infinitivo передает не столько значение долженствования, исходящее из внешних условий (обстоятельства, моральный долг), сколько помогает передать чувства главного героя - несмотря на то, что мужчине мучительно осознавать реальную ситуацию, которая причиняет ему боль и беспокойство, он стремится достичь цели. Haber de + infinitivo в настоящем контексте по функциям приближается к Futuro Simple и Modo Imperativo.

«- Procuro cumplir lo mejor posible con mi deber profesional, y ya que tengo que ganarme la vida...

- Eso de tener que ganarte la vida... - empezó a decir don Fermín.» [5, c. 71].

Из диалога Евгении и дона Фермина ясно, что женщина оценивает свою ответственность как внутреннюю потребность исполнить долг. Именно конструкция tener que + infinitivo позволяет подчеркнуть, что именно Евгения является ответственной за свою судьбу. Иными словами, значение tener que + infinitivo имеет конкретную отнесенность к говорящему, позволяя читателю определить, кто является исполнителем действия/воли.

В следующих примерах, напротив, присутствует общая, обезличенная конструкция hay que + infinitivo. Ocoбенность употребления такой конструкции в том, что она указывает не столько на лицо, сколько подчеркивает важность исполнения определенного действия, продиктованного внешними причинами.

«Hay que ganarla a puño!» [5, c 74]

«Y hay que confundir. Confundir sobre todo, confundirlo todo.» [5, c. 215]

«Porque hay que ponerse en todo.» [5, c. 185]

«Hay que digerir la felicidad!» [5, c. 185]

"Le digo a usted, tía, que me la ha de pagar. Me la ha de pagar ese...» [5, c. 115]

Евгения уверяет свою тетю в том, что Аугусто должен ответить за содеянное. Модальная конструкция выражает не просто долженствование, а угрозу, т.к. женщина словесно «наказывает» обидчика, оценивая его действия как неадекватные.

"- Que hay que casarse con ellos. Para eso han nacido y 
son buenos, para maridos.»

«- Pero si no le quiero, ¿cómo he de casarme con él?» $[5$, c 116$]$

В данном примере hay que + infinitivo служит для передачи субъективного мнения, однако, перенесенного на объективный план. Тетя Евгении выражает свою мысль выдавая ее за истину, в то время как племянница не соглашается принять условия тети, отвечая ей вопросительным предложением, в котором присутствует конструкция haber de + infinitivo, которая в данном случае выражает отказ от вынужденности, необходимости исполнять чужую волю. Помимо отказа выполнять действие, конструкция передает недоумение по поводу сделанного предложения.

"Cuando estuvieron en la calle, Víctor comenzó:

- Ya sabes, Augusto, que me tuve que casar muy joven...

- ¿Que te tuviste que casar?» [5, c. 106]

Друг Аугусто, Виктор, рассказывает мужчине о том, что его судьба была решена против его же воли. Конструкция tener que + infinitivo в настоящем контексте имеет несколько обобщенное значение, поскольку действие было выполнено над говорящим, без его согласия. Такое обобщенное значение говорит о резко отрицательной оценке Виктором произошедшего, смещая фокус субъективной модальности на более общий, объективный план.

«- Y ¿por qué no me he de burlar? Tú, querido experimentador, la quisiste tomar de rana, y es ella la que te ha tomado de rana a ti.» [5, c.215].

В обращении Виктора конструкция haber de + infinitivo c частицей no передает сопротивление подчиняться правилам. Виктор пытается продемонстрировать намерение противостоять обычным схемам поведения и по этой же причине старается «уколоть» Аугусто.

"iQué dulzura debe de ser olvidarse de la vida y de la muerte entre sus brazos!, ¡dejarse brezar en ellos como en olas de carne!» [5, c.81].
В этом примере конструкция deber de+ infinitivo передает оценку говорящим предполагаемой ситуации. Здесь конструкция передает долженствование не в привычной функции, а в значении «должно бы/должно быть» в смысле предположения. Аугусто предстваляет, как ему может быть хорошо, если он окажется в обществе приятной незнакомки.

Анализ материала показал, что грамматизованная конструкция tener que + infinitivo имеет отнесенность к конкретному лицу, но передает долженствование/ необходимость, исходящие извне, или значение обязательства, которое говорящий по субъективным или объективным причинам считает необходимым исполнить. Конструкция haber de + infinitivo по своему значению приближается к конструкции tener que + infinitivo, однако первая имеет более интенсивное значение морального долга и предрешенности. Конструкция deber de + infinitivo имеет значение долженствования, но с большим процентом вероятности или предположения. Безличная конструкция hay que + infinitivo переносит акцент не на исполнителя действия, а на само действие. Данная конструкция носит обобщающий характер и может переносить высказывание на объективный план.

Согласно результатам проведенного исследования, было выявлено, что область субъективно-модальных значений грамматических конструкций включает целое множество значений, таких как необходимость, сомнение, желание, возможность, предположение. На данные смыслы могут накладываться дополнительные значения эмоционального плана, такие как: страх, удивление, негодование, угроза и т.д.

Наиболее ярко субъективно-оценочный компонент проявляется на уровне грамматических средств, таких как конструкции, выражающие долженствование. Данное исследование может получить развитие и быть дополнено сравнительным анализом передачи средств субъективной модальности текста оригинала и перевода.

\section{ЛИТЕРАТУРА}

1. Васильева-Шведе 0.К., Степанов Г.В. Теоретическая грамматика испанского языка: Морфология и синтаксис частей речи / О.К. Васильева-Шведе, В.К. Степанов. - М.: Высшая школа, 1972. - 349 с.

2. Виноградов В.В. Избранные труды. Исследования по русской грамматике / В.В. Виноградов. - М., 1975. - 559 с.

3. Романова Т.В. Модальность. Оценка. Эмоциональность / Т.В. Романова. - Нижний Новгород: НЛГУ им. Н.А. Добролюбова, $2008 .-309$ с.

4. Селезнева Л.В. Текстовая модальность в разных типах дискурса / Л.В. Селезнева // Ученые записки РГСУ. Филология и искусствоведение. - 2009. Вып.6. - С. 199-203.

5. Унамуно М. Туман. Niebla / Miguel de Unamuno. - СПб.: Антология, КАРO, 2006. - 256 c.

6. Шевцова М.А. специфика использования средств выражения модальности вынужденности в романе Э. Мендосы «Sin noticias de Gurb» [Электронный ресурс]. - Режим доступа:http://moglobi.ru/stati/m-a-shevcova-rostov-na-donu-specifika-ispolezovaniya-sredstv-v/main.html (дата 0бращения: 15.08.2020).

(с) Палий Юлия Владимировна (julmay19@gmail.com).

Журнал «Современная наука: актуальные проблемы теории и практики» 